\title{
«Intavulare». Tables de chansonniers romans. II. Chansonniers français (série coordonnée par Madeleine Tyssens)
}

\section{Walter Meliga}

\section{(2) OpenEdition}

\section{Journals}

\section{Edizione digitale}

URL: http://journals.openedition.org/studifrancesi/7469

DOI: $10.4000 /$ studifrancesi.7469

ISSN: 2421-5856

\section{Editore}

Rosenberg \& Sellier

\section{Edizione cartacea}

Data di pubblicazione: 1 décembre 2009

Paginazione: 601

ISSN: 0039-2944

\section{Notizia bibliografica digitale}

Walter Meliga, ««Intavulare». Tables de chansonniers romans. II. Chansonniers français (série coordonnée par Madeleine Tyssens)», Studi Francesi [Online], 159 (LIII | III) | 2009, online dal 30 novembre 2015, consultato il 09 janvier 2021. URL: http://journals.openedition.org/studifrancesi/7469 ; DOI: https:// doi.org/10.4000/studifrancesi.7469

Questo documento è stato generato automaticamente il 9 janvier 2021.

\section{cc) $($ ) $\ominus$}

Studi Francesi è distribuita con Licenza Creative Commons Attribuzione - Non commerciale - Non opere derivate 4.0 Internazionale. 


\title{
«Intavulare». Tables de chansonniers romans. II. Chansonniers français (série coordonnée par Madeleine Tyssens)
}

\author{
Walter Meliga
}

\section{NOTIZIA}

«Intavulare». Tables de chansonniers romans. II. Chansonniers français (série coordonnée par Madeleine TYSSENS). 4. Z (Siena, Biblioteca Comunale H.X.36), par Lucilla SPETIA, Liège, Publications de la Faculté de Philosophie et Lettres (diffusion Droz, Genève), 2006 («Documenta et Instrumenta», 4), pp. $133+4$ tavv. f.t.

1 Il progetto internazionale «Intavulare», diretto da Anna Ferrari, ha per scopo la pubblicazione di più serie di volumi contenenti le tavole dei componimenti, degli autori e degli incipit di tutti i canzonieri romanzi medievali; l'edizione delle tavole è accompagnata da un'introduzione codicologica che illustra la struttura, i contenuti e la storia del canzoniere. Si tratta di un progetto del più grande interesse per la storia della lirica romanza, e in particolare della formazione e della diffusione del canone di questa poesia nelle tradizioni linguistiche considerate. Il progetto si divide in quattro sezioni, dedicate rispettivamente ai canzonieri provenzali, francesi, italiani e galegoportoghesi: della seconda, coordinata da Madeleyne Tyssens, sono già usciti, prima di quelli qui annunciati, i volumi dedicati ai canzonieri $H$ e $Z^{a}$ («Intavulare». Tables de chansonniers romans. II. Chansonniers français. 2. H (Modena, Biblioteca Estense) $\mathrm{Z}^{\mathrm{a}}$ (Bibliothèque Métropolitaine de Zagreb), par Lucilla SPETIA, Liège, Publications de la Faculté de Philosophie et Lettres, 1997), a, b e A («Intavulare». Tables de chansonniers romans. II. Chansonniers français. 1. a (B.A.V., Reg. lat. 1490), b (B.A.V., Reg. lat. 1522), A (Arras, Bibliothèque Municipale 657), par Madeleine TYSSENS, Città del Vaticano, Biblioteca Apostolica Vaticana, 1998) e C («Intavulare». Tables de chansonniers romans. II. 
Chansonniers français. 3. C (Bern, Burgerbibliothek 389), par Paola MORENO, Liège, Publications de la Faculté de Philosophie et Lettres, 1999).

2 Questi due ultimi volumi riguardano il grande canzoniere parigino $U$ e il più piccolo $Z$, della Biblioteca Comunale di Siena. Di quest'ultimo, la curatrice offre una dettagliata introduzione, che continua e approfondisce il lavoro a suo tempo fatto da Marcello Spaziani nella sua edizione critica (Il canzoniere francese di Siena (Biblioteca Comunale, $\mathrm{H}^{-}$ $X-36)$. Introduzione, testo critico e traduzione, Firenze, Olschki, 1957). 